LEITE, G.L.D.; COSTA, C.A.; ALMEIDA, C.I.M.; PICANÇO, M. Efeito da adubação sobre a incidência de traça-do-tomateiro e alternaria em plantas de tomate. Horticultura Brasileira, Brasília, v. 21, n. 3, p. 448-451, julho-setembro 2003.

\title{
Efeito da adubação sobre a incidência de traça-do-tomateiro e alternaria em plantas de tomate
}

\author{
Germano L.D. Leite ${ }^{1}$; Cândido A. da Costa ${ }^{1}$; Chrystian I.M. Almeida ${ }^{1}$; Marcelo Picanço ${ }^{2}$ \\ ${ }^{1}$ UFMG, C. Postal 135, 39400-006 Montes Claros-MG; E-mail: gldleite@ufmg.br; ²UFV, Depto. Biologia Animal, 36 571-000, Viçosa-MG
}

\section{RESUMO}

Avaliou-se o efeito de quatro níveis de adubação nitrogenada e potássica (NK) na resposta do tomateiro Lycopersicon esculentum, c.v Santa Clara, ao ataque de mancha de alternaria (Alternaria solani), e da traça-do-tomateiro (Tuta absoluta), em casa de vegetação, em três diferentes idades da planta. O delineamento experimental foi blocos casualizados com sete repetições, no esquema fatorial $3 \times 4$. Foram avaliados a altura da planta $(\mathrm{cm})$, área foliar $\left(\mathrm{cm}^{2}\right)$ e o número de cachos por planta, flores por cacho, flores abortadas por cacho, frutos por cacho, frutos com mancha de alternaria por cacho, frutos atacados por traça-do-tomateiro por cacho, peso dos frutos por planta e minas de traça-de-tomateiro. A maior percentagem de frutos atacados pela traça foi observado em plantas de tomate cultivadas com altas doses de $\mathrm{N}$. Com o aumento do número de flores ocorreu menor número de frutos atacados por alternaria. Tanto o ataque de $A$. solani como o de traça-do-tomateiro foi concentrado em frutos de menor peso, sendo que quanto maior o número de flores atacadas por $A$. solani, menor foi o ataque da traça aos frutos. $\mathrm{O}$ ataque da traça aos frutos foi maior em plantas de dois meses do que em plantas de quatro meses de idade, sendo o mesmo observado para o número de minas da traça-do-tomateiro.

Palavras-chave: Lycopersicon esculentum, Tuta absoluta, Alternaria solani, nitrogênio, potássio.

\begin{abstract}
Effect of fertilization on the incidence of leafminer and early blight on tomato plants
\end{abstract}

The effect of NK fertilization on tomato plants (Lycopersicon esculentum), cv. "Santa Clara", over early blight (Alternaria solani) and the leafminer (Tuta absoluta) attack in greenhouse, in the different plant ages, was evaluated. The $3 \times 4$ factorial experiment was established in a randomized blocks design with seven replicates. Plant height $(\mathrm{cm})$, leaf area $\left(\mathrm{cm}^{2}\right)$ and number of raceme per plant, number of flowers per raceme, flower drop per raceme, number of fruits per raceme, damaged fruits per raceme by early blight and leafminer, fruit weight per plant and number of mines of leafminer were evaluated. Greater percentage of fruits damaged by leafminer was observed in the tomato plants grown under higher $\mathrm{N}$ levels. Positive correlation between number of flowers and of fruits with $A$. solani attack were observed. A. solani and T. absoluta attacks was concentrated in fruits with smaller weight. Nevertheless, with the increase of flowers damaged by $A$. solani a decrease in the percentage of fruits attacked by $T$. absoluta was observed. Tomato plants two months old showed higher percentage of fruits damaged by $T$. absoluta and number of mines of this insect than on plants four months old.

Keywords: Lycopersicon esculentum, Tuta absoluta, Alternaria solani, nitrogen, potassium.

\section{(Recebido para publicação em 14 de agosto de 2001 e aceito em 25 de março de 2003)}

A cultura do tomateiro requer cuidados especiais quanto à sua nutrição, irrigação, controle de pragas e de doenças, colheita e armazenamento. Dentre as pragas e doenças mais importantes desta cultura tem-se a traça-dotomateiro [Tuta absoluta (Meyrick) (Lepidoptera: Gelechiidae)], e a mancha de alternaria (Alternaria solani), que atacam folhas, flores e frutos (Picanço et al., 1998). O ataque de pragas e/ou doenças pode afetar ou ser afetado por características morfofisiológicas das plantas. Fery \& Cuthbert (1973) observaram que a Heliothis zea (Bod.) (Lepidoptera: Noctuidae) ataca preferencialmente frutos menores de tomate. Leite (1997) observou que o aumento do teor de nitrogênio $(\mathrm{N})$ nas folhas de tomateiro reduziu a mortalidade larval de traça-do-tomateiro. Bergamin Filho et al. (1995) notaram que característi- cas e condições morfofisiológicas de uma planta, tais como injúrias, estado nutricional e estádio de desenvolvimento da planta, interferem em sua suscetibilidade a doenças.

A adubação nitrogenada e potássica (K) afeta as características vegetativas e reprodutivas das plantas (Malavolta $e t$ al., 1989; Marschner, 1995). O N potencializa e incrementa a síntese de proteínas e de ácidos nucléicos, além de promover o crescimento vegetativo e a formação de gemas floríferas e frutíferas (Marschner, 1995). O K está relacionado com a síntese de proteínas (RNA tradutor) e de carboidratos, promove o armazenamento de açúcares e amido, além de estimular o crescimento vegetativo da planta, a melhor utilização da água e a resistência a pragas e doenças (Malavolta et al., 1989; Marschner, 1995). A idade fisiológica das plantas também pode apresentar diversas reações ao estímulo do meio, modificando a sua morfologia e rotas metabólicas (Larcher, 1986).

Estudou-se o efeito de níveis de adubação NK na resposta do tomateiro ao ataque de alternaria e de traça-do-tomateiro em plantas de dois, três e quatro meses de idade.

\section{MATERIAL E MÉTODOS}

O experimento foi conduzido, em casa de vegetação, de maio a dezembro de 1996, na UFV, MG. As parcelas experimentais foram constituídas por vasos de polietileno de cinco $\mathrm{Kg}$, com uma planta cada. O delineamento experimental foi blocos casualizados com sete repetições, no esquema fatorial $3 \times 4$ (três idades de planta $\mathrm{x}$ quatro níveis de adubação), totalizando 84 parcelas. Avaliou- 
Tabela 1. Área foliar e percentagem de frutos atacados por traça-do-tomateiro em função dos níveis de adubação em plantas de tomateiro. Viçosa, UFV, 1996.

\begin{tabular}{|c|c|c|}
\hline Adubação & Área foliar $\left(\mathrm{cm}^{2}\right)$ & Frutos atacados $(\%)$ \\
\hline $\mathrm{N}_{100} \mathrm{~K}_{0}$ & $281,75 \mathrm{~B}$ & $3,53 \% A B$ \\
\hline $\mathrm{N}_{100} \mathrm{~K}_{200}$ & $260,33 \mathrm{~B}$ & $3,26 \% \mathrm{~B}$ \\
\hline $\mathrm{N}_{300} \mathrm{~K}_{0}$ & $370,76 \mathrm{~A}$ & $5,08 \% \mathrm{~A}$ \\
\hline $\mathrm{N}_{300} \mathrm{~K}_{200}$ & $370,73 \mathrm{~A}$ & $4,49 \% A B$ \\
\hline C.V. $(\%)$ & 33,73 & 60,65 \\
\hline
\end{tabular}

Médias seguidas pela mesma letra na coluna não diferem estatisticamente, entre si, pelo teste de Tukey, a $5 \%$ de probabilidade. C.V. $=$ coeficiente de variação.

Tabela 2. Percentagem de nitrogênio e de potássio na matéria seca foliar em função de níveis de adubação e idade de plantas de tomateiro. Viçosa, UFV, 1996.

\begin{tabular}{|c|c|c|c|}
\hline \multicolumn{4}{|c|}{ Nitrogênio (\%) } \\
\hline \multirow{2}{*}{ Adubação } & \multicolumn{3}{|c|}{ Idade das plantas } \\
\hline & Dois meses & Três meses & Quatro meses \\
\hline$\overline{\mathrm{N}_{100} \mathrm{~K}_{0}}$ & $2,91 \mathrm{Ca}$ & $2,00 \mathrm{Ab}$ & $1,93 \mathrm{Ab}$ \\
\hline $\mathrm{N}_{100} \mathrm{~K}_{200}$ & $2,61 \mathrm{Ca}$ & $1,98 \mathrm{Ab}$ & $1,85 \mathrm{Ab}$ \\
\hline $\mathrm{N}_{300} \mathrm{~K}_{0}$ & $4,61 \mathrm{Aa}$ & $2,51 \mathrm{Ab}$ & $1,95 \mathrm{Ac}$ \\
\hline $\mathrm{N}_{300} \mathrm{~K}_{200}$ & $3,92 \mathrm{Ba}$ & $2,27 \mathrm{Ab}$ & $1,92 \mathrm{Ac}$ \\
\hline Média geral & $3,51 \mathrm{a}$ & $2,19 b$ & $1,92 \mathrm{c}$ \\
\hline C.V. (\%) & & 17,50 & \\
\hline \multicolumn{4}{|c|}{ Potássio (\%) } \\
\hline \multirow{2}{*}{ Adubação } & \multicolumn{3}{|c|}{ Idade das plantas } \\
\hline & Dois meses & Três meses & Quatro meses \\
\hline $\mathrm{N}_{100} \mathrm{~K}_{0}$ & $3,14 \mathrm{Ba}$ & $1,29 \mathrm{Cb}$ & $1,05 \mathrm{Bb}$ \\
\hline $\mathrm{N}_{100} \mathrm{~K}_{200}$ & $4,75 \mathrm{Aa}$ & $2,35 \mathrm{Bb}$ & $2,23 \mathrm{Ab}$ \\
\hline $\mathrm{N}_{300} \mathrm{~K}_{0}$ & $2,78 \mathrm{Ba}$ & $1,58 \mathrm{Cb}$ & $0,72 \mathrm{Bc}$ \\
\hline $\mathrm{N}_{300} \mathrm{~K}_{200}$ & $4,44 \mathrm{Aa}$ & $3,10 \mathrm{Ab}$ & $1,81 \mathrm{Ac}$ \\
\hline Média geral & $3,78 \mathrm{a}$ & $2,08 \mathrm{~b}$ & $1,45 \mathrm{c}$ \\
\hline C.V. $(\%)$ & & 27,25 & \\
\hline
\end{tabular}

Médias seguidas pela mesma letra maiúscula na coluna e minúsculas na linha não diferem estatisticamente, entre si, pelo teste de Tukey, a $5 \%$ de probabilidade. C.V. $=$ coeficiente de variação.

se o efeito de quatro níveis de adubação NK no plantio $\left[\mathrm{N}_{100} \mathrm{~K}_{0}\left(100 \mathrm{mg}\right.\right.$ de N... $\mathrm{kg}^{-1}$ de solo); $\mathrm{N}_{100} \mathrm{~K}_{200}$ (100mg de N.kg-1 de solo e $200 \mathrm{mg}$ de $\mathrm{K} . \mathrm{kg}^{-1}$ de solo); $\mathrm{N}_{300} \mathrm{~K}_{0}$ (300mg de N.kg-1 de solo); $\mathrm{N}_{300} \mathrm{~K}_{200}$ (300mg de N.kg-1 de solo e $200 \mathrm{mg}$ de $\mathrm{K} . \mathrm{kg}^{-1}$ de solo)] na resposta do tomateiro cv. Santa Clara, ao ataque de alternaria e de traça-do-tomateiro em plantas de dois, três e quatro meses após a emergência. O solo utilizado no experimento foi Latossolo Vermelho Amarelo Eutrófico.

No início das avaliações foram liberados 400 adultos de traça-do-tomateiro. A infestação de $A$. solani ocorreu naturalmente. Avaliou-se a altura da planta $(\mathrm{cm})$, área foliar $\left(\mathrm{cm}^{2}\right)$ utilizando o Sistema de Medição de Área Foliar Delta T (Bacarin, 1995) (três folhas ao longo do dossel das plantas por tratamento) e o número de cachos por planta, flores por cacho, flores abortadas por cacho, frutos por cacho, frutos com mancha de alternaria por cacho, frutos atacados por traça-do-tomateiro por cacho, peso dos frutos por planta (Picanço et al., 1998) e minas de traça-de-tomateiro (três folhas ao longo do dossel das plantas), semanalmente, em cada tratamento (Picanço et al., 1995).

Para avaliação dos teores de $\mathrm{N}$ e de $\mathrm{K}$ nas folhas, quando as plantas atingi- ram dois, três e quatro meses de idade, foi feita a retirada de três folhas ao longo do dossel de três plantas de cada tratamento. Essas folhas foram acondicionadas em saco de papel Kraft, e levados para estufa com circulação de ar (a $67^{\circ} \mathrm{C}$ ), permanecendo aí por três dias. Após secagem, as amostras foram passadas em moinho Willey, peneira 20 malhas. As análises de $\mathrm{N}$ e de $\mathrm{K}$ foram realizadas em laboratório da UFV, seguindo metodologias propostas por Jackson (1958).

Os dados foram submetidos à análise de variância e as médias comparadas pelo teste de Tukey a 5\% de probabili- 
Tabela 3. Altura de plantas, número de flores e de frutos por cacho em função de níveis de adubação e idade de plantas de tomateiro. Viçosa, UFV, 1996.

\begin{tabular}{|c|c|c|c|}
\hline \multicolumn{4}{|c|}{ Altura das Plantas (cm) } \\
\hline \multirow{2}{*}{ Adubação } & \multicolumn{3}{|c|}{ Idade das plantas } \\
\hline & Dois meses & Três meses & Quatro meses \\
\hline$\overline{\mathrm{N}_{100} \mathrm{~K}_{0}}$ & $118,00 \mathrm{Bc}$ & $163,40 \mathrm{Ab}$ & $195,75 \mathrm{Aa}$ \\
\hline $\mathrm{N}_{100} \mathrm{~K}_{200}$ & $124,20 \mathrm{ABb}$ & $160,40 \mathrm{Aa}$ & $164,25 \mathrm{Aa}$ \\
\hline $\mathrm{N}_{300} \mathrm{~K}_{0}$ & $118,80 \mathrm{Bc}$ & $150,80 \mathrm{Ab}$ & $189,40 \mathrm{Aa}$ \\
\hline $\mathrm{N}_{300} \mathrm{~K}_{200}$ & $149,20 \mathrm{Ab}$ & 166,80 Aab & $197,20 \mathrm{Aa}$ \\
\hline Média geral & $127,55 \mathrm{c}$ & $160,35 \mathrm{~b}$ & 187,39 a \\
\hline C.V. (\%) & & 29,47 & \\
\hline \multicolumn{4}{|c|}{ Flores por cacho $\left(n^{\circ}\right)$} \\
\hline \multirow{2}{*}{ Adubação } & \multicolumn{3}{|c|}{ Idade das plantas } \\
\hline & Dois meses & Três meses & Quatro meses \\
\hline $\mathrm{N}_{100} \mathrm{~K}_{0}$ & $07,40 \mathrm{ABa}$ & $14,00 \mathrm{Aa}$ & $14,80 \mathrm{Aa}$ \\
\hline $\mathrm{N}_{100} \mathrm{~K}_{200}$ & $06,60 \mathrm{Ba}$ & $09,00 \mathrm{Aa}$ & $12,80 \mathrm{Aa}$ \\
\hline $\mathrm{N}_{300} \mathrm{~K}_{0}$ & $13,20 \mathrm{ABa}$ & $15,80 \mathrm{Aa}$ & $14,40 \mathrm{Aa}$ \\
\hline $\mathrm{N}_{300} \mathrm{~K}_{200}$ & $15,40 \mathrm{Aa}$ & $09,40 \mathrm{Aa}$ & $10,60 \mathrm{Aa}$ \\
\hline Média geral & $10,65 \mathrm{a}$ & $12,05 \mathrm{a}$ & $13,15 a$ \\
\hline C.V. $(\%)$ & & 25,28 & \\
\hline \multicolumn{4}{|c|}{ Frutos por cacho $\left(n^{\circ}\right)$} \\
\hline \multirow{2}{*}{ Adubação } & \multicolumn{3}{|c|}{ Idade das plantas } \\
\hline & Dois meses & Três meses & Quatro meses \\
\hline$\overline{\mathrm{N}_{100} \mathrm{~K}_{0}}$ & $11,00 \mathrm{Aa}$ & $24,40 \mathrm{Aa}$ & $18,00 \mathrm{BCa}$ \\
\hline $\mathrm{N}_{100} \mathrm{~K}_{200}$ & $14,80 \mathrm{Aa}$ & $25,60 \mathrm{Aa}$ & $15,20 \mathrm{Ca}$ \\
\hline $\mathrm{N}_{300} \mathrm{~K}_{0}$ & $8,20 \mathrm{Ab}$ & $29,40 \mathrm{Aa}$ & $31,20 \mathrm{ABa}$ \\
\hline $\mathrm{N}_{300} \mathrm{~K}_{200}$ & $8,00 \mathrm{Ab}$ & $25,80 \mathrm{Aa}$ & $36,40 \mathrm{Aa}$ \\
\hline Média geral & $10,50 \mathrm{~b}$ & $26,30 \mathrm{a}$ & $25,20 \mathrm{a}$ \\
\hline C.V. $(\%)$ & & 60,65 & \\
\hline
\end{tabular}

Médias seguidas pela mesma letra maiúscula na coluna e minúsculas na linha não diferem estatisticamente, entre si, pelo teste de Tukey, a $5 \%$ de probabilidade. C.V. = coeficiente de variação.

dade. Foi efetuada ainda análise de correlação de Pearson (Snedecor, 1970).

\section{RESULTADOS E DISCUSSÃO}

As folhas de tomateiro apresentaram maiores áreas sob os níveis de adubação $\mathrm{N}_{300} \mathrm{~K}_{0}$ e $\mathrm{N}_{300} \mathrm{~K}_{200}$ e menores sob os níveis $\mathrm{N}_{100} \mathrm{~K}_{0}$ e $\mathrm{N}_{100} \mathrm{~K}_{200}$ (Tabela 1). Este resultado deve-se, provavelmente, à maior concentração de $\mathrm{N}$ no início do desenvolvimento das plantas (Tabela 2), corroborando com os relatados por Marschner (1995) e Malavolta et al. (1989). Não se detectou efeito significativo da idade das plantas quanto à área foliar. Aos dois meses de idade as plantas mais altas foram observadas sob o nível de adubação $\mathrm{N}_{300} \mathrm{~K}_{200}$ (Tabela 3), devendo-se, provavelmente, aos elevados teores de N e de K (Tabela 2). Entretanto, não se observou efeito de adubação na altura das plantas aos três e quatro meses de idade (Tabela 3).

Não se detectou efeito significativo dos níveis de adubação sobre o número de cachos por planta $(4,89)$. O menor número de flores por cacho foi observado no nível de adubação $\mathrm{N}_{100} \mathrm{~K}_{200} \mathrm{em}$ plantas de dois meses de idade (Tabela 3). Não se observou efeito significativo dos níveis de adubação sobre o número de flores por cacho em plantas de três e quatro meses de idade bem como da idade das plantas sobre o número de flores por cacho. $\mathrm{O}$ maior número de frutos por cacho foi observado em plantas de qua- tro meses de idade cultivadas sob o nível de adubação $\mathrm{N}_{300} \mathrm{~K}_{200}$, superior estatisticamente aos níveis $\mathrm{N}_{100} \mathrm{~K}_{0}$ e $\mathrm{N}_{100} \mathrm{~K}_{200}$. A idade das plantas e os níveis de adubação não afetaram o peso dos frutos $(42,89 \mathrm{~g})$. Em geral, o aumento nas concentrações de NK acarretou incremento no número de flores por cacho (Tabelas 2 e 3), sendo que o $\mathrm{N}$ e $\mathrm{K}$ estão envolvidos na formação de gemas reprodutivas, desta forma refletindo na produção da planta (Malavolta et al.,1989; Marschner, 1995).

Quanto maior o número de flores por planta, maior foi o número de cachos por planta $(\mathrm{r}=0,35) \mathrm{e}$, consequentemente, o número de frutos por planta $(\mathrm{r}=0,35)$. Contudo, o toma- 
teiro produz uma grande quantidade de flores, ocorrendo um abortamento natural destas $(\mathrm{r}=0,38)$. Esse fato, possivelmente se deve à produção insuficiente de fotoassimilados em relação ao grande número de flores (Picanço et al.,1998).

Observou-se correlação positiva entre o número de flores e de frutos com a incidência de $A$. solani ( $\mathrm{r}=0,38$ e r $=0,40$; respectivamente), ou seja, quanto maior o número de flores e de frutos nas plantas maior o ataque observado por este fungo, talvez devido a uma maior fonte de recursos. Contudo, com o aumento do número de flores ocorreu menor número de frutos atacados por esse fungo na planta $(\mathrm{r}=-0,25)$. Uma possível explicação para esse fato é que quanto maior o número de flores menor seria a probabilidade dos esporos caírem sobre os frutos, ou seja, teria ocorrido efeito de diluição, como postulado por Canerday et al. (1969) para H. zea em frutos de tomate. Tanto o ataque de $A$. solani como o de traça-do-tomateiro concentrou-se em frutos de menor peso $(r=-0,26$ e $r=-0,20$, respectivamente), sendo que o mesmo fato foi observado por Fery \& Cuthbert (1973) para a $H$. zea. As pragas em questão preferiram atacar frutos com a mesma idade fisiológica, porém, de menor tamanho.

A maior incidência de minas de traça-do-tomateiro provocou redução no número de cachos por planta $(\mathrm{r}=-0,54)$ e, consequentemente, de frutos por planta $(\mathrm{r}=-0,54)$. Esse fato, provavelmente, se deve à redução da superfície fotossinteticamente ativa das folhas do tomateiro, além das injúrias diretas sobre as flores. Verificou-se que quanto maior o número de cachos e de flores

Tabela 4. Número de cachos por planta e percentagem de frutos atacados por traça-dotomateiro em função da idade da planta de tomateiro. Viçosa, UFV, 1996.

\begin{tabular}{lcc}
\hline \multicolumn{1}{c}{ Idade } & Cachos por planta $\left(\mathbf{n}^{\circ}\right)$ & Frutos com traça (\%) \\
\hline Dois meses & $3,60 \mathrm{~B}$ & $8,72 \mathrm{~A}$ \\
Três meses & $5,45 \mathrm{~A}$ & $5,53 \mathrm{~B}$ \\
Quatro meses & $5,60 \mathrm{~A}$ & $1,98 \mathrm{C}$ \\
\hline C.V. \% & 12,80 & 37,99 \\
\hline
\end{tabular}

Médias seguidas pela mesma letra na coluna não diferem estatisticamente, entre si, pelo teste de Tukey, a $5 \%$ de probabilidade. C.V. $=$ coeficiente de variação.

por planta maior foi o ataque de traçado-tomateiro ao fruto $(\mathrm{r}=0,23$ e $\mathrm{r}=0,35$; respectivamente). Todavia, quanto mais flores atacadas por A. solani menor o ataque de traça-do-tomateiro aos frutos $(\mathrm{r}=-0,23)$, provavelmente, devido a menor produção de frutos e consequentemente, a uma menor fonte de recursos para a traça-do-tomateiro e/ ou a rejeição deste aos frutos atacados pelo fungo. $\mathrm{O}$ ataque da traça-do-tomateiro aos frutos foi maior em plantas de dois meses do que em plantas de quatro meses de idade (Tabela 4), sendo o mesmo observado para o número de minas da praga $(\mathrm{r}=-0,91)$. A maior percentagem de frutos atacados por traça foi observada em plantas cultivadas sob o nível de adubação $\mathrm{N}_{300} \mathrm{~K}_{0}$ e a menor em $\mathrm{N}_{100} \mathrm{~K}_{200}$ (Tabela 1). Provavelmente, plantas cultivadas sob alta adubação nitrogenada e baixa adubação potássica apresentaram alta concentração foliar de $\mathrm{N}$ (Tabela 2), mais favorável ao inseto (Leite, 1997).

\section{LITERATURA CITADA}

BACARIN, M.A. Fotossintese, partição de biomassa e fixação de dinitrogênio em relação a produção do feijoeiro (Phaseolus vulgaris $L$.). 1995. 71 p. (Tese doutorado), UFV, Viçosa.
BERGAMIN FILHO, A.; KIMATI, H.; AMORIM, L. Manual de Fitopatologia: Principios e conceitos. São Paulo: Agronômica Ceres, 1995. V. 1, 919 p.

CANERDAY, T.D.; TODD, J.W.; DILBECK, J.D. Evaluation of tomatoes for fruitworm resistance. Journal of Georgia Entomological Society, v. 4, p. 51-54, 1969.

FERY, R.L.; CUTHBERT JR, F.P. Factors Affecting Evaluation of Fruitworm Resistence in the Tomato. Journal of the American Society for Horticultural Science, v. 98, n. 5, p. 457-459, 1973. JACKSON, M.L. Soil chemical analysis. New Jersey: Prentice Hall, 1958. 498 p.

LARCHER, W. Ecofisiologia Vegetal. São Paulo: 319p. E.P.U., 1986.

LEITE, G.L.D. Efeito da idade, parte do dossel e niveis de adubação na resistência de Lycopersicon hirsutum f. glabratum à Tuta absoluta. $199740 \mathrm{p}$. (Tese mestrado), UFV, Viçosa.

MALAVOLTA, E.; VITTI, G.C.; DE OLIVEIRA, S. Avaliação do estado nutricional das Plantas: Princípios e aplicações. Piracicaba: Associação Brasileira para Pesquisa da Potassa e do Fosfato, 1989. 201 p.

MARSCHNER, H. Mineral nutrition of higher plants. San Diego: Academic Press, 1995. 889 p. PICANÇO, M.; SILVA, D.J.H.; LEITE, G.L.D.; MATA, A.C.; JHAM, G.N. Intensidade de ataque de Scrobipalpula absoluta (Meyrick, 1917) (Lepidoptera: Gelechiidae) ao dossel de três espécies de tomateiro. Pesquisa Agropecuária Brasileira, Brasília, v. 30, n. 4, p. 429-433,1995.

PICANÇO, M.; LEITE, G.L.D.: GUEDES, R.N.C.; SILVA, E.A. Yield loss in trellised tomato affected by insecticidal sprays and plant spacing. Crop Protection, v. 17, n. 5, p. 447-452,1998.

SNEDECOR, G.W. Métodos estadisticos aplicados a la investigacion agrícola y biológica. México: Compañia Editorial Continental, 1970. 626 p. 